\title{
SIMILARIDADE DE ATRIBUTOS FíSICO-QUÍMICOS COM USO DE ANÁLISE MULTIVARIADA APLICADA À GESTÃO QUALITATIVA DE ÁGUAS SUBTERRÂNEAS
}

\author{
SIMILARITY OF PHYSICAL-CHEMICAL ATTRIBUTES WITH USE OF MULTIVARIATE \\ ANALYSIS APPLIED TO THE QUALITATIVE MANAGEMENT OF UNDERGROUND WATERS
}

\author{
Maria da Conceição Rabelo GOMES ${ }^{1}$, Luiz Alberto Ribeiro MENDONÇA ${ }^{1}$, Maria \\ Gorethe de Sousa LIMA ${ }^{1}$, Adriana Oliveira ARAÚJO².
}

(1) Universidade Federal do Cariri, Av. Tenente Raimundo Rocha S/N - Cidade Universitária, 63048-080, Juazeiro do

Norte, Ceará, conceicaorabelo@yahoo.com.br, larm@ufc.br, gorethelima@cariri.ufc.br.

(2) Instituto Federal de Educação, Ciência e Tecnologia da Paraíba, Campus Princesa Isabel, Rodovia PB-426 S/N -

Sitio Barro Vermelho, 58755-000, Triunfo, Paraíba, adrianasaneamento050@gmail.com

\author{
Introdução \\ Material e Métodos \\ Resultados e Discussão \\ Conclusão \\ Agradecimentos \\ Referências
}

\begin{abstract}
RESUMO - Em regiões sedimentares, os recursos hídricos subterrâneos constituem uma reserva hídrica inestimável, notadamente em regiões de escassez quantitativa e/ou qualitativa dos recursos hídricos superficiais. Como a utilização das águas subterrâneas para fins diversos também está condicionada a qualidade, neste trabalho desenvolveu-se uma metodologia utilizando a técnica da análise fatorial, associada a análise de agrupamento multivariada, objetivando dar suporte à gestão qualitativa. Foram identificadas similaridades entre atributos físico-químicos capazes de explicar possíveis processos responsáveis pela qualidade das águas, tomando como estudo de caso a região de CRAJUBAR, no Vale do Cariri cearense. A análise fatorial aplicada a atributos físico-químicos identificou dois componentes responsáveis por aproximadamente $84 \%$ da variância total. O primeiro como indicador de poluição das águas subterrâneas por esgoto $\left(\mathrm{Mg}^{2+}, \mathrm{K}^{+}, \mathrm{Cl}^{-}, \mathrm{NO}_{2}{ }^{-}, \mathrm{NO}_{3}{ }^{-}\right.$e Condutividade Elétrica) e o segundo, como indicador da dissolução dos minerais calcita e gipsita $\left(\mathrm{Ca}^{2+}, \mathrm{SO}_{4}{ }^{2-}\right.$ e $\left.\mathrm{HCO}_{3}{ }^{-}\right)$. A análise de agrupamento multivariada por componente, nos períodos chuvoso e seco, apresentou três grupos identificados por amostras com diferentes faixas de concentrações. A evolução dos grupos, do período chuvoso para o seco, mostrou processos físico-químicos dinâmicos responsáveis pela poluição e estacionários, pela dissolução dos minerais.
\end{abstract}

Palavras-chave: Constituintes Iônicos, Análise de Agrupamento, Água Subterrânea.

ABSTRACT - In sedimentary regions, groundwater resources are an invaluable water reserves, notably in areas of shortage quantitative and/or qualitative of surface water resources. As the use of groundwater for various purposes are also subject to quality, this work developed a methodology using the technique of factor analysis, coupled with multivariate cluster analysis, aiming to support the qualitative management. Similarities were found between physical and chemical attributes can explain possible processes responsible for water quality, taking as a case study to Crajubar region of Vale Cariri Cearense. Factor analysis applied to physical and chemical properties identified two components account for approximately $84 \%$ of the total variance. The first indicator as pollution of groundwater by sewage $\left(\mathrm{Mg}^{2+}, \mathrm{K}^{+}, \mathrm{Cl}^{-}, \mathrm{NO}_{2}{ }^{-}, \mathrm{NO}_{3}{ }^{-}\right.$and Electrical Conductivity) and the second, as dissolution of the indicator minerals calcite and gypsum $\left(\mathrm{Ca}^{2+}, \mathrm{SO}_{4}{ }^{2-}\right.$ e $\left.\mathrm{HCO}_{3}{ }^{-}\right)$. The multivariate cluster analysis by component, in the rainy and dry seasons, had three groups identified by samples with different concentrations of tracks. The evolution of the groups, the rainy season to the dry, showed physical and chemical processes responsible for dynamic and stationary pollution, the dissolution of minerals.

Keywords: Ionic Constituents, Cluster Analysis, Groundwater.

\section{INTRODUÇÃO}

A pesquisa foi desenvolvida no Vale do Cariri, situado no setor leste da Bacia Sedimentar do Araripe, envolvendo parte dos municípios de Crato, Juazeiro do Norte e Barbalha (CRAJUBAR), com uma população estimada para 2014 de aproximadamente 450.000 habitantes. Dentre estes municípios, Juazeiro do Norte é o mais populoso, com aproximadamente 264.000 habitantes e densidade demográfica de 1.004 habitantes/ $\mathrm{km}^{2}$ (IBGE, 2015). Nesta área os recursos hídricos subterrâneos explotados no aquífero arenítico Rio da Batateira são a única fonte de abastecimento público e privado. Atualmente a demanda hídrica está forçando uma superexplotação, que é observada na intermitência da rede de drenagem natural, antes perene e hoje perenizada por esgotos domésticos e industriais.

Nessa conjuntura a preservação da qualidade da água como uma necessidade universal exige atenção por parte das autoridades sanitárias e consumidores em geral, particularmente no que se refere aos mananciais destinados ao consumo 
humano.

A qualidade da água é definida por sua composição e pelos efeitos que seus constituintes podem causar a organismos (Santos, 2008). Neste contexto o estudo das águas subterrâneas sob o ponto de vista da hidrogeoquímica pode contribuir com informações acerca do funcionamento de aquíferos, inclusive sob interferências antrópicas. A partir desses estudos pode-se aferir processos de dissolução/precipitação, transporte de poluentes, evolução de plumas de poluição, etc.

Desde os primeiros contatos com as rochas, as águas naturais e o ambiente geológico estão submetidos a processos geoquímicos que dependem basicamente da composição química das águas que abastecem os aquíferos e do ambiente geológico, de fatores físicos do subsolo e das águas e da influência humana sobre as águas e o meio ambiente geológico (Fenzl, 1988).

As modificações de parâmetros físicoquímicos de águas subterrâneas resultante da interação com minerais, vem sendo estudada desde a década de 60 (Garrels \& Mackenzie, 1967). Nesse mesmo período também iniciaram os primeiros estudos no semiárido nordestino, desenvolvidos por Teixeira \& Oliveira (1962) e Costa (1965). Na Bacia Sedimentar do Araripe também foram realizados estudos hidrogeoquímicos que contribuíram com o entendimento da evolução da composição química das águas de percolação através de diferentes sistemas aquíferos, inclusive fornecendo subsídio para a compreensão da dinâmica de fluxo local e regional (Santiago et al., 1997; Mendonça et al., 1998; Machado et al., 2008; Mendonça et al., 2008; Lima et al., 2011; Santos et al., 2014).

Para a determinação da qualidade da água subterrânea são requeridas medidas de diversas variáveis físico-químicas, com variação temporal e espacial, apresentando característica multivariada. Nesse aspecto utiliza-se como ferramenta apropriada a estatística multivariada. A análise estatística multivariada permite efetuar uma visão global do fenômeno, utilizando simultaneamente todas as variáveis na interpretação teórica do conjunto de dados obtidos (Everitt \& Dunn, 1991). Entre as técnicas de estatística multivariada empregadas em estudos de qualidade das águas subterrâneas, objetivando identificar as principais variáveis responsáveis por mudanças qualitativas, encontra-se a análise de agrupamento. Estudos utilizando essa ferramenta foram desenvolvidos por Vidal \& Kiang (2002); Brito et al. (2006), Cloutier et al. (2008), Machado et al. (2008), Andrade et al. (2010), Fernandes et al. (2010) e Salgado et al. (2011).

O presente trabalho teve por objetivo identificar a similaridade das variáveis determinantes da qualidade das águas subterrâneas na região de CRAJUBAR, no Vale do Cariri cearense, identificando possíveis processos hidrogeoquímicos, utilizando a técnica da análise fatorial associada a análise de agrupamento multivariada.

\section{MATERIAL E MÉTODOS}

A área de estudo envolve parte dos municípios de CRAJUBAR (9185000 $9215000 \mathrm{~N}$ e 450000 - $475000 \mathrm{~S}$, Zona 24S, SAD-69 datum) (Figura 1), que possui clima tipo tropical quente semiárido, no Vale do Cariri e tropical quente semiárido brando, na Chapada do Araripe, com temperatura média de 24 a $26{ }^{\circ} \mathrm{C}$ e precipitação pluvial média anual de $925 \mathrm{~mm}$, com período chuvoso de janeiro a maio (IPECE, 2015).

$\mathrm{Na}$ área de estudo aflora predominantemente a formação Rio da Batateira, caracterizada por arenitos argilosos médios a finos, com espessura média de $200 \mathrm{~m}$, cimentada na base por siltitos argilosos e folhelhos betuminosos e fossilíferos (Ponte \& Appi, 1990), constituindo o aquífero explotado mais importante.

Esta formação geológica constitui a base do Grupo Araripe (Mesozoica), que é sotoposta a outras formações na Chapada do Araripe: a Santana, que é composta predominantemente por calcita, gipsita e folhelhos; a Arajara, por siltitos, argilitos e arenitos finos argilosos; e a Exú, por arenitos friáveis, argilosos, de granulometria variável, aflorante no topo da Chapada (Ponte \& Appi, 1990). As formações Arajara e Exú são caracterizadas como aquíferos e a Santana, como aquiclude. 


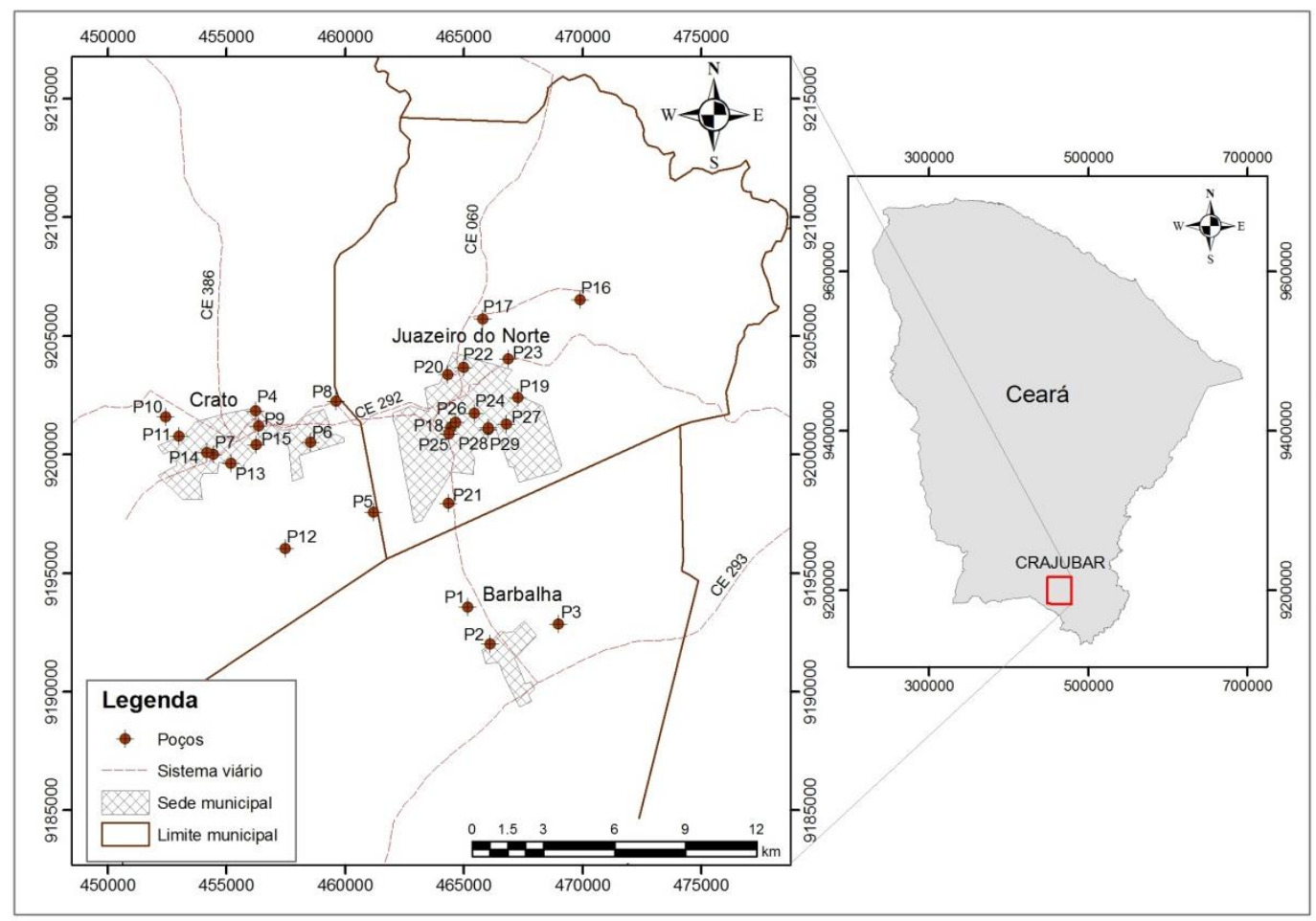

Figura 1 - Localização da área de pesquisa e dos pontos amostrados.

Sotopostos à formação Rio da Batateira encontram-se as formações Abaiara, Missão Velha, que são aquíferos, e a Brejo Santo, que é um aquiclude, pertencentes ao Grupo Vale do Cariri (Mesozoica). Cimentando a base desse pacote sedimentar, encontra-se a formação Mauriti (Paleozoica), que é um aquífero, depositada sobre rochas do embasamento précambriano.

Nesse estudo utilizou-se o banco de dados hidroquímicos da Companhia de Gestão dos Recursos Hídricos do Estado do Ceará (COGERH, 2011), com informações de 28 poços distribuídos na região de CRAJUBAR.

Os dados hidroquímicos foram analisados em dois períodos distintos do ano de 2011: o mês de abril, caracterizando o período chuvoso, e o mês de outubro, o seco.

Os atributos físico-químicos considerados nesta investigação foram: cálcio $\left(\mathrm{Ca}^{2+}\right)$, magnésio $\left(\mathrm{Mg}^{2+}\right)$, sódio $\left(\mathrm{Na}^{+}\right)$, potássio $\left(\mathrm{K}^{+}\right)$, bicarbonato $\left(\mathrm{HCO}_{3}^{-}\right)$, cloreto $\left(\mathrm{Cl}^{-}\right)$, sulfato $\left(\mathrm{SO}_{4}{ }^{2-}\right)$, ferro $\left(\mathrm{Fe}^{3+}\right)$, amônia $\left(\mathrm{NH}_{4}{ }^{+}\right)$, nitrito $\left(\mathrm{NO}_{2}^{-}\right)$, nitrato $\left(\mathrm{NO}_{3}^{-}\right), \mathrm{pH}$, turbidez, dureza total, condutividade elétrica e sólidos totais dissolvidos. Considerando os 28 poços e as análises realizadas nos períodos chuvoso e seco (16 atributos por período), totalizaram-se 896 atributos físico-químicos analisados.

A análise estatística iniciou com a avaliação do grau de associação entre os atributos, através da matriz de correlação de Pearson. Em seguida, aplicou-se a técnica da análise fatorial, buscando identificar dimensões de variabilidade comuns (ou fatores) existentes em um conjunto de fenômenos, com o intuito de desvendar estruturas existentes, mas não observáveis diretamente. $\mathrm{Na}$ análise fatorial utilizou-se o método das componentes principais, utilizando-se a rotação varimax normalizada. Tal abordagem buscou descrever as relações de covariância entre os atributos correlacionados, com base nos fatores identificados, além de evidenciar, por meio de comunalidades, o quanto cada atributo explica cada fator (Hoffmann, 1992; Manly, 1998; Araújo et al., 2013). A verificação da adequação dos dados à análise fatorial foi feita a partir do índice KMO (Kaiser-Meyer-Olkin Measure of Sampling Adequacy) e do teste estatístico de esfericidade de Bartlett, que testa a hipótese nula de que as variáveis analisadas não são correlacionadas (Hair Jr. et al., 1998; Araújo et al., 2013).

Por último, realizou-se o agrupamento das amostras a partir do maior número de atributos explicados por um único fator da análise fatorial. Nessa técnica, utilizou-se o método Ward como critério hierárquico de agrupamento, com medida de similaridade dada 
pela distância euclidiana quadrada (squared euclidean distance). Esse critério hierárquico de agrupamento utiliza a soma total dos quadrados dos desvios de cada objeto em relação à média do grupo onde o mesmo foi inserido. A escolha deste critério se fundamentou na frequente empregabilidade do mesmo em estudos de qualidade da água (Vega et al., 1998; Andrade et al., 2008; Yidana et al., 2008; Palácio et al., 2009; Fernandes et al., 2010; Salgado et al., 2011). O agrupamento foi apresentado por meio de um dendrograma e o ponto de "corte", utilizado na definição do número de grupos, foi definido na maior variação da distância reescalonada do coeficiente de aglomeração (Ferreira, 1996).

Os grupos formados pela técnica do agrupamento tiveram suas médias comparadas pelo teste $\mathrm{t}$ de Student aos níveis de 5\% e 1\%, após execução da análise de variância. Estes testes indicam as variáveis responsáveis pela formação dos grupos na análise multivariada.

Essas análises estatísticas foram processadas no software SPSS Statistics, versão 17.0.

\section{RESULTADOS E DISCUSSÃO}

A Tabela 1 mostra a estatística descritiva das concentrações e medidas dos atributos físico-químicos utilizados neste trabalho, nos períodos seco e chuvoso.

Tabela 1 - Estatística descritiva das concentrações e medidas dos atributos físico-químicos nos períodos seco e chuvoso, com $n=28$

\begin{tabular}{lcccc|cccc}
\hline \multirow{2}{*}{ Atributo } & \multicolumn{3}{c}{ Período seco (outubro/ 2011) } & \multicolumn{4}{c}{ Período chuvoso (abril/ 2011) } \\
\cline { 2 - 8 } & $x_{\min }$ & $x_{\max }$ & $\bar{x}$ & \multicolumn{1}{c|}{$c$ v } & $x_{\min }$ & $x_{\max }$ & $\bar{x}$ & $c v$ \\
\hline $\mathrm{Ca}^{2+}$ & 3.2 & 128.0 & 25.7 & 96.7 & 3.2 & 134.4 & 25.9 & 103.6 \\
$\mathrm{Mg}^{2+}$ & 1.0 & 46.7 & 15.3 & 73.3 & 2.9 & 36.9 & 16.8 & 58.0 \\
$\mathrm{Na}^{+}$ & 8.0 & 71.5 & 22.3 & 74.0 & 6.0 & 69.4 & 21.9 & 75.2 \\
$\mathrm{~K}^{+}$ & 5.3 & 35.9 & 13.7 & 55.0 & 4.7 & 43.8 & 13.4 & 74.2 \\
$\mathrm{HCO}_{3}{ }^{-}$ & 12.9 & 549.2 & 119.5 & 98.8 & 6.5 & 516.9 & 101.5 & 105.6 \\
$\mathrm{Cl}^{-}$ & 9.6 & 198.3 & 45.9 & 86.7 & 9.6 & 226.9 & 53.5 & 87.0 \\
$\mathrm{SO}_{4}{ }^{2-}$ & 0.1 & 30.3 & 5.5 & 152.6 & 0.1 & 79.8 & 17.5 & 140.8 \\
$\mathrm{Fe}^{3+}$ & 0.0 & 1.9 & 0.3 & 128.1 & 0.0 & 0.1 & 0.0 & 66.1 \\
$\mathrm{NH}_{4}{ }^{+}$ & 0.0 & 0.3 & 0.1 & 55.0 & 0.0 & 0.5 & 0.3 & 79.2 \\
$\mathrm{NO}_{2}{ }^{-}$ & 0.0 & 1.5 & 0.3 & 106.7 & 0.5 & 2.3 & 0.8 & 46.9 \\
$\mathrm{NO}_{3}{ }^{-}$ & 1.4 & 112.0 & 35.5 & 91.8 & 1.4 & 40.3 & 18.9 & 72.9 \\
$\mathrm{pH}^{\mathrm{T}}$ & 4.1 & 7.9 & 6.2 & 16.3 & 4.0 & 7.5 & 5.8 & 14.8 \\
$\mathrm{DT}$ & 0.3 & 12.0 & 1.2 & 242.3 & 0.2 & 3.8 & 0.7 & 97.2 \\
$\mathrm{CE}$ & 4.0 & 400.0 & 122.6 & 73.9 & 12.0 & 440.0 & 122.3 & 76.5 \\
$\mathrm{STD}$ & 82.0 & 1193.0 & 422.0 & 64.4 & 90.0 & 1139.0 & 378.5 & 68.7 \\
\hline
\end{tabular}

Legenda- Concentrações iônicas em mg/L; T: turbidez (UT); DT: dureza total (mg/L de $\mathrm{CaCO}_{3}$ ); CE: condutividade elétrica $(\mu \mathrm{S} / \mathrm{cm})$; STD: sólidos totais dissolvidos $(\mathrm{mg} / \mathrm{L}) ; x_{\min }$ : valor mínimo; $x_{\max }$ : valor máximo; $\bar{x}$ : valor médio; cv: coeficiente de variação $(\%)$.

As águas do aquífero foram caracterizadas quanto a abundância dos íons, a partir do diagrama de Piper, utilizando as 56 amostras divididas entre os períodos seco e chuvoso (Figura 2). O diagrama foi construído a partir do software Qualigraf (Mobus, 2003).

Quanto à abundância de cátions, das 28 amostras coletadas no período chuvoso, $46 \%$ foram sódicas, $42 \%$ mistas, $8 \%$ magnesianas e $4 \%$ cálcicas. Quanto aos ânions, $54 \%$ foram bicarbonatadas, $38 \%$ cloretadas e $8 \%$ mistas (Figura 2). Já para o período seco, quanto aos cátions, das 28 amostras, $46 \%$ foram sódicas e mistas e $8 \%$ cálcicas. Quanto aos ânions,
$65 \%$ foram bicarbonatadas e $35 \%$ cloretadas. Nesse contexto, quanto aos cátions, do período chuvoso para o seco, verifica-se o desaparecimento das amostras magnesianas e uma discreta elevação de amostras mistas e cálcicas. Já quanto aos ânions, observa-se o desaparecimento das águas mistas, uma discreta redução das cloretadas e uma elevação de $11 \%$ nas bicarbonatadas.

$\mathrm{O} \mathrm{CO}_{2}$ presente na zona não saturada do aquífero Rio da Batateira proporciona a ocorrência de reações químicas capazes de levar ao acréscimo de $\mathrm{HCO}_{3}{ }^{-}$nas amostras do período chuvoso para o seco. 


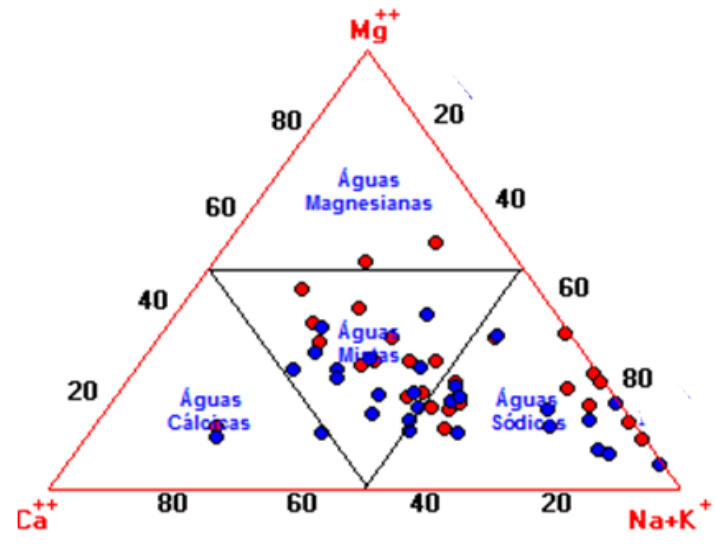

CÁTIONS

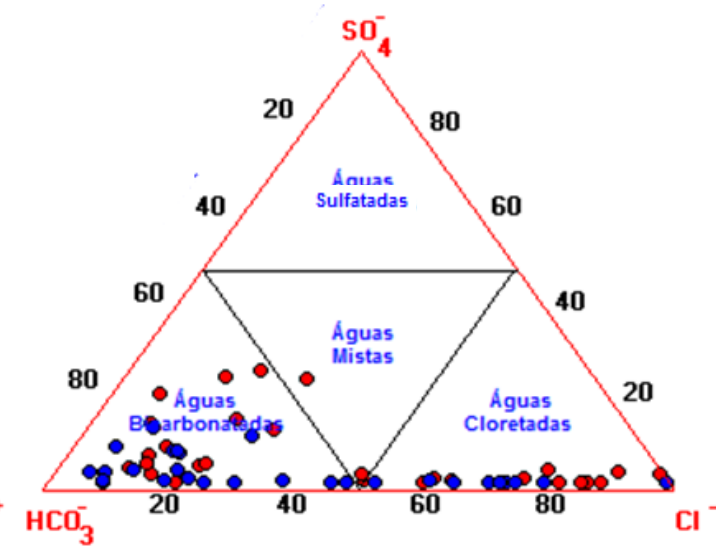

ÂNIONS

Legenda:

- Período chuvoso (28 amostras)

- Período seco (28 amostras)

Figura 2 - Caracterização iônica das águas subterrâneas nos períodos seco e chuvoso.

A primeira reação ocorre através da dissolução do gás carbônico na água de recarga (Equação 1). Em seguida o gás dissolvido interage com a água, produzindo ácido carbônico (Equação 2). Por fim ocorre a dissociação do ácido carbônico em água, originando bicarbonatos (Equação 3) e carbonatos (Equação 4).

$$
\begin{aligned}
& \mathrm{CO}_{2 \text { (gasoso) }} \leftrightarrow \mathrm{CO}_{2 \text { (aquoso) }} \\
& \mathrm{CO}_{2 \text { (aquoso) }}+\mathrm{H}_{2} \mathrm{O} \leftrightarrow \mathrm{H}_{2} \mathrm{CO}_{3} \\
& \mathrm{H}_{2} \mathrm{CO}_{3}^{-} \leftrightarrow \mathrm{H}^{+}+\mathrm{H}_{2} \mathrm{CO}_{3}^{-} \\
& \mathrm{HCO}_{3}^{-} \leftrightarrow \mathrm{H}^{+}+\mathrm{CO}_{3}{ }^{2-}
\end{aligned}
$$

Inicialmente, foram utilizados os 16 atributos físico-químicos na análise fatorial. Nesta primeira análise verificou-se que os índices KMO obtidos para o conjunto de atributos analisados, para os períodos chuvoso e seco, foram de respectivamente 0,432 e 0,378 e os testes estatísticos de esfericidade de Bartlett não se mostraram significativos a $p<0,01$. Esses resultados indicam que os fatores encontrados na Análise Fatorial não descreveram adequadamente a variação dos dados originais. Nesse contexto, quatro dos 16 atributos analisados $\left(\mathrm{Na}^{+}, \mathrm{Fe}^{3+}, \mathrm{NH}_{4}^{+}\right.$e turbidez $)$ apresentaram baixa comunalidade (inferior a 0,600).

Os 12 atributos restantes foram utilizados numa segunda simulação, na qual verificou-se que os índices KMO permaneceram baixos para ambos os períodos e os testes estatísticos de esfericidade de Bartlett continuaram sem significância. Nessa simulação, três dos 12 atributos restantes ( $\mathrm{pH}$, dureza total e STD) continuaram apresentando baixa comunalidade.

Em uma terceira simulação, os três atributos que apresentaram baixa comunalidade foram desconsiderados e os modelos apresentaram resultados favoráveis para nove atributos no período chuvoso $\left(\mathrm{Ca}^{2+}, \mathrm{Mg}^{2+}, \mathrm{K}^{+}, \mathrm{HCO}_{3}{ }^{-}, \mathrm{Cl}^{-}\right.$, $\mathrm{SO}_{4}{ }^{2-}, \mathrm{NO}_{2}{ }^{-}, \mathrm{NO}_{3}{ }^{-}$e $\mathrm{CE}$ ) e oito no período seco (com exceção do $\mathrm{NO}_{2}{ }^{-}$), com índices $\mathrm{KMO}$ de respectivamente 0,662 e 0,525 , para os períodos chuvoso e seco e testes de esfericidade de Bartlett significativos a $\mathrm{p}<0,01$.

Na Tabela 2 encontram-se as matrizes de correlação para os atributos analisados na terceira simulação. Observa-se que 64 dos coeficientes de correlação, $75 \%$ do total de pares, apresentaram valores significativos. Destes, cerca de $42 \%$ encontram-se no intervalo $0,6 \leq|\mathrm{r}|<0,9$, caracterizados, segundo Callegari-Jacques (2003), como de correlação forte. O restante $(33 \%)$ encontra-se no intervalo $0,3 \leq|\mathrm{r}|<0,6$, caracterizados como de correlação moderada.

A matriz de correlação para o período chuvoso (Tabela 2) mostra que a $\mathrm{CE}$ possui correlação forte com o $\mathrm{Ca}^{2+}, \mathrm{Mg}^{2+}, \mathrm{K}^{+}, \mathrm{Cl}^{-} \mathrm{e}$ $\mathrm{NO}_{2}^{-}$, indicando possível influência desses íons no aumento da salinidade das águas na área. $\mathrm{O}$ íon $\mathrm{NO}_{2}^{-}$correlacionou-se positivamente com $\mathrm{Mg}^{2+}, \mathrm{Cl}^{-}, \mathrm{NO}_{3}^{-}$e $\mathrm{CE}$, indicando a possível relação destes íons com fontes de poluição de origem orgânica recente. 
Tabela 2 - Matriz de correlação dos atributos físico-químicos das águas da região de CRAJUBAR, com destaque para as correlações fortes.

\begin{tabular}{|c|c|c|c|c|c|c|c|c|c|c|}
\hline & Atributo & $\mathrm{Ca}^{2+}$ & $\mathbf{M g}^{2+}$ & $\mathbf{K}^{+}$ & $\mathrm{HCO}_{3}^{-}$ & $\mathrm{Cl}^{-}$ & $\mathrm{SO}_{4}{ }^{2-}$ & $\mathrm{NO}_{2}^{-}$ & $\mathrm{NO}_{3}^{-}$ & $\mathbf{C E}$ \\
\hline \multirow{9}{*}{ 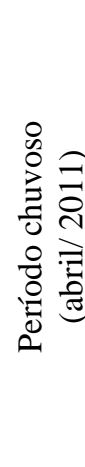 } & $\mathrm{Ca}^{2+}$ & 1.00 & & & & & & & & \\
\hline & $\mathrm{Mg}^{2+}$ & $0.54 *$ & 1.00 & & & & & & & \\
\hline & $\mathrm{K}^{+}$ & -0.10 & $0.41 *$ & 1.00 & & & & & & \\
\hline & $\mathrm{HCO}_{3}^{-}$ & 0.87 * & 0.22 & -0.45 & 1.00 & & & & & \\
\hline & $\mathrm{Cl}^{-}$ & 0.34 & $0.77^{*}$ & $0.76^{*}$ & -0.11 & 1.00 & & & & \\
\hline & $\mathrm{SO}_{4}{ }^{2-}$ & $0.49^{*}$ & 0.16 & -0.30 & $0.64 *$ & -0.15 & 1.00 & & & \\
\hline & $\mathrm{NO}_{2}^{-}$ & 0.14 & $0.74 *$ & $0.59 *$ & -0.22 & 0.80 * & -0.13 & 1.00 & & \\
\hline & $\mathrm{NO}_{3}^{-}$ & -0.04 & $0.55^{*}$ & $0.83 *$ & -0.42 & 0.80 * & -0.38 & $0.65^{*}$ & 1.00 & \\
\hline & $\mathrm{CE}$ & $0.72 *$ & $0.84 *$ & $0.51^{*}$ & 0.37 & $0.86^{*}$ & 0.25 & $0.64 *$ & $0.59 *$ & 1.00 \\
\hline \multirow{9}{*}{ 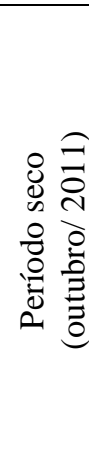 } & $\mathrm{Ca}^{2+}$ & 1.00 & & & & & & - & & \\
\hline & $\mathrm{Mg}^{2+}$ & 0.39 & 1.00 & & & & & - & & \\
\hline & $\mathrm{K}^{+}$ & -0.23 & 0.38 & 1.00 & & & & - & & \\
\hline & $\mathrm{HCO}_{3}^{-}$ & 0.87 * & 0.20 & -0.46 & 1.00 & & & - & & \\
\hline & $\mathrm{Cl}^{-}$ & 0.31 & $0.74 *$ & 0.70* & -0.08 & 1.00 & & - & & \\
\hline & $\mathrm{SO}_{4}{ }^{2-}$ & $0.49^{*}$ & 0.04 & -0.35 & $0.67 *$ & -0.19 & 1.00 & - & & \\
\hline & $\mathrm{NO}_{2}^{-}$ & - & - & - & - & - & - & - & - & - \\
\hline & $\mathrm{NO}_{3}{ }^{-}$ & -0.06 & $0.67 *$ & $0.76^{*}$ & -0.39 & $0.87 *$ & -0.40 & - & 1.00 & \\
\hline & $\mathrm{CE}$ & $0.70^{*}$ & $0.76^{*}$ & 0.41 & 0.43 & $0.84 *$ & 0.23 & - & $0.63 *$ & 1.00 \\
\hline
\end{tabular}

* valores significativos com $\mathrm{p}<0,05$.

Já o íon $\mathrm{HCO}_{3}{ }^{-}$apresentou correlação forte e positiva com o $\mathrm{Ca}^{2+}$ e o $\mathrm{SO}_{4}^{2-}$, sugerindo que estes atributos são, possivelmente, provenientes da dissolução dos minerais presentes na formação Santana da Chapada do Araripe.

Para o período seco, a matriz de correlação apresenta semelhanças com a do período chuvoso, com exceção do $\mathrm{NO}_{2}^{-}$, que é ausente, e do $\mathrm{NO}_{3}{ }^{-}$, que apresentou correlação com o $\mathrm{Mg}^{2+}$ e com a CE.

Os íons associados ao $\mathrm{NO}_{2}^{-}$e $\mathrm{NO}_{3}{ }^{-}$estão relacionados à contaminação de origem orgânica da água subterrânea por atividades humanas, incluindo práticas agrícolas em áreas de baixio (através do uso de fertilizantes) e a disposição inadequada de entulhos da construção civil às margens de cursos d'água.

$\mathrm{Na}$ área de estudo é comum o lançamento de efluentes não tratados em rios $\mathrm{e}$ riachos, introduzindo quantidades elevadas de carbono orgânico solúvel, nitrogênio, cloretos, potássio e magnésio nas águas superficiais, que por conexão são capazes de atingir os aquíferos. Ao atingir o aquífero, estes íons podem adquirir uma razoável mobilidade, capaz de alcançar eventualmente áreas que teoricamente seriam de baixo risco de contaminação por uma dessas atividades humanas (Lucena et al., 2004).
Pesquisa realizada por Santos et al (2014), em uma bateria de poços que explota água para o abastecimento público da cidade de Juazeiro do Norte, utilizou o íon cloreto como traçador no estudo da conexão entre um riacho perenizado por esgoto e o aquífero, mostrando que o transporte de contaminante ocorre, predominantemente, na vertical, induzido pelo bombeamento dos poços e pela recarga do aquífero a partir do riacho. Na mesma bateria de poços, Franca et al. (2006) também observaram que as águas explotadas por parte dos poços apresentaram indícios de poluição por esgotos domésticos. Machado (2005) também observou uma forte correlação entre as concentrações de nitrato com cloreto e com CE de amostras de águas subterrâneas coletadas nos municípios de Juazeiro do Norte e Crato. Segundo o autor, elevados valores de CE, nestas condições, pode ser um indicativo de contaminação por esgoto doméstico.

Os íons $\mathrm{Ca}^{2+} \mathrm{e} \mathrm{SO}_{4}^{2-}$, associados ao $\mathrm{HCO}_{3}{ }^{-}$, sugerem uma mistura entre águas subterrâneas recarregadas no Vale e águas que contribuíram com a dissolução dos minerais calcita $\left(\mathrm{CaCO}_{3}\right)$ e gipsita $\left(\mathrm{CaSO}_{4} \cdot 2 \mathrm{H}_{2} \mathrm{O}\right)$, presentes na Formação Santana da Chapada do Araripe. A reação de dissociação da calcita é dada pelas Equações 5, 
6 e 7 , tendo como produto os íons $\mathrm{Ca}^{2+}{\mathrm{e} \mathrm{HCO}_{3}}^{-}$ , nas proporções 1:1 (Equações 5 e 6) e 1:2 (Equação 7). A reação de dissociação da gipsita é dada pela Equação 8, tendo como produto os íons $\mathrm{SO}_{4}{ }^{2-}, \mathrm{Ca}^{2+}$ e $\mathrm{HCO}_{3}{ }^{-}$, nas proporções $1: 1: 1$. Considerando $\mathrm{pH} 7$, temperatura de $25^{\circ} \mathrm{C}$ e pressão total de 1 bar, as solubilidades da calcita e gipsita são de respectivamente 100 e $2.100 \mathrm{mg} / \mathrm{L}$ (Freeze \& Cherry, 1979). Nesse contexto, o acréscimo de $\mathrm{HCO}_{3}{ }^{-}$nas amostras do período chuvoso para o seco, já observado no diagrama de Piper, não pode ser explicado apenas a partir das reações produzidas pelo $\mathrm{CO}_{2}$ presente na zona não saturada do aquífero Rio da Batateira.

$$
\begin{aligned}
& \mathrm{CaCO}_{3}+\mathrm{H}^{+} \leftrightarrow \mathrm{Ca}^{2+}+\mathrm{HCO}_{3}^{-} \\
& \mathrm{CaCO}_{3}+\mathrm{H}_{2} \mathrm{O} \leftrightarrow \mathrm{Ca}^{2+}+\mathrm{HCO}_{3}^{-}+\mathrm{OH}^{-} \\
& \mathrm{CaCO}_{3}+\mathrm{H}_{2} \mathrm{CO}_{3} \leftrightarrow \mathrm{Ca}^{2+}+2 \mathrm{HCO}_{3}^{-} \\
& \mathrm{H}_{2} \mathrm{O}+\mathrm{CO}_{2}+\mathrm{CaSO}_{4} \cdot 2 \mathrm{H}_{2} \mathrm{O} \leftrightarrow \mathrm{H}^{+}+\mathrm{HCO}_{3}^{-}+\mathrm{Ca}^{2+}+\mathrm{SO}_{4}^{2-}+2 \mathrm{H}_{2} \mathrm{O}
\end{aligned}
$$

A Formação Rio da Batateira é caracterizada por arenitos argilosos. A fração argila presente nos solos da área, caracterizada por difração de raios X, apresenta predominância do argilomineral caulinítico 1:1 (Silva, 2013). A composição química da caulinita é expressa pela fórmula $\mathrm{Si}_{2} \mathrm{Al}_{2} \mathrm{O}_{5}(\mathrm{OH})_{4}$. Como o quartzo e as argilas são produtos finais no processo de intemperismo gerado pela hidrólise parcial dos feldspatos, é provável que também ocorra precipitação de argila (Equação 9), resultando também na liberação do íon $\mathrm{K}^{+}$.

$$
2 \mathrm{KAlSi}_{3} \mathrm{O}_{8}+11 \mathrm{H}_{2} \mathrm{O} \rightarrow \mathrm{Si}_{2} \mathrm{Al}_{2} \mathrm{O}_{5}(\mathrm{OH})_{4}+4 \mathrm{H}_{4} \mathrm{SiO}_{4}+2 \mathrm{~K}^{+}+2 \mathrm{OH}^{-}
$$

Outro processo possível é o de troca iônica

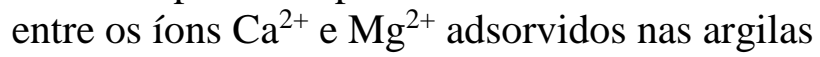
da formação Rio da Batateira, representadas pelo X nas Equações 10 e 11.

$\mathrm{Ca}^{2+}+2 \mathrm{X}^{-} \rightarrow \mathrm{CaX}_{2}$

$$
\mathrm{Mg}^{2+}+2 X^{-} \rightarrow M g X_{2}
$$

$\mathrm{Na}$ zona vadosa a mobilidade do $\mathrm{Mg}^{2+}$ lixiviado no perfil depende da existência de outros ânions na solução do solo, particularmente do $\mathrm{NO}_{3}{ }^{-}$e do $\mathrm{Cl}^{-}$, oriundos da mineralização da matéria orgânica (Pearson et al., 1962; Gonzalez-Erico et al., 1979), tendo como fonte principal o lançamento de esgoto não tratado na área.

Os resultados da análise fatorial apresentaram dois fatores, tanto para o período chuvoso, quanto para o seco, com autovalores superiores a um (Tabela 3). Para o período chuvoso, o primeiro fator apresentou uma contribuição para explicação da variância total dos atributos de aproximadamente $51 \%$ e o segundo de $32 \%$. Já para o período seco, o primeiro fator apresentou aproximadamente $48 \%$ e o segundo 37\%. Estes resultados indicam que os dois fatores respondem por aproximadamente $83 \%$ da variância dos dados, para o período chuvoso e $85 \%$ para o seco.

Para o período chuvoso, o primeiro fator apresentou uma contribuição para explicação da variância total do conjunto amostral de aproximadamente $51 \%$, mostrando uma alta correlação entre os atributos $\mathrm{Mg}^{2+}, \mathrm{K}^{+}, \mathrm{Cl}^{-}$, $\mathrm{NO}_{2}{ }^{-}$e $\mathrm{NO}_{3}{ }^{-}$, reforçando a hipótese da diluição de esgoto percolado nos aquíferos, tendo, consequentemente, grande correlação com a $\mathrm{CE}$, indicando a importância desse processo no aumento da salinidade das águas. Já no período seco, o primeiro fator corresponde a $48 \%$ de toda variância do conjunto amostral. No entanto, apenas o íon $\mathrm{NO}_{2}^{-}$não aparece como atributo, indicando uma possível oxidação do mesmo para $\mathrm{NO}_{3}{ }^{-}$(Equação 12), do período chuvoso para o seco. Nesse caso, a recarga nas áreas antropizadas seria uma possível fonte de contaminação recente. $\mathrm{O} \mathrm{NO}_{3}{ }^{-}$tem alta mobilidade nos sistemas aeróbicos de águas subterrâneas, como em aquíferos onde os níveis estáticos encontram-se pouco profundos ou as condutividades hidráulicas são relativamente elevadas. Nestes meios, o $\mathrm{NO}_{3}^{-}$move-se sem retardamento, podendo atingir extensas áreas.

$2 \mathrm{NO}_{2}^{-}+\mathrm{O}_{2} \leftrightarrow 2 \mathrm{NO}_{3}^{-}+$Energia

O segundo fator, tanto para o período chuvoso quanto para o seco, corresponde a respectivamente 33 e $37 \%$ de toda a variância do conjunto amostral, mostrando uma alta correlação entre $\mathrm{Ca}^{2+}, \mathrm{SO}_{4}{ }^{2-}$ e $\mathrm{HCO}_{3}{ }^{-}$, reforçando a hipótese da dissolução dos minerais calcita e gipsita presentes na Formação Santana da Chapada do Araripe, sem, no entanto, contribuir fortemente com a salinidade das águas explotadas no Vale do Cariri. 
Tabela 3 - Cargas fatoriais, comunalidades e variância explicada na análise fatorial dos nove atributos analisados, após a rotação pelo método varimax.

\begin{tabular}{|c|c|c|c|c|c|c|}
\hline \multirow[t]{3}{*}{ Atributo } & \multicolumn{3}{|c|}{ Período chuvoso (abril/ 2011) } & \multicolumn{3}{|c|}{ Período seco (outubro/ 2011) } \\
\hline & \multicolumn{2}{|c|}{ Carga Fatorial } & \multirow{2}{*}{ Comunalidade } & \multicolumn{2}{|c|}{ Carga Fatorial } & \multirow{2}{*}{ Comunalidade } \\
\hline & Fator 1 & Fator 2 & & Fator 1 & Fator 2 & \\
\hline $\mathbf{M g}^{2+}$ & 0,818 & 0,387 & 0,819 & $\mathbf{0 , 8 2 9}$ & 0,243 & 0,745 \\
\hline $\mathbf{K}^{+}$ & 0,798 & $-0,374$ & 0,777 & 0,725 & $-0,478$ & 0,753 \\
\hline $\mathrm{Cl}^{-}$ & 0,971 & 0,033 & 0,945 & 0,971 & $-0,017$ & 0,944 \\
\hline $\mathrm{NO}_{2}^{-}$ & 0,855 & $-0,057$ & 0,734 & - & - & - \\
\hline $\mathrm{NO}_{3}^{-}$ & 0,866 & $-0,337$ & 0,863 & 0,907 & $-0,346$ & 0,943 \\
\hline $\mathrm{Ca}^{2+}$ & 0,297 & 0,901 & 0,901 & 0,303 & 0,896 & 0,894 \\
\hline $\mathrm{HCO}_{3}^{-}$ & $-0,142$ & 0,954 & 0,931 & $-0,040$ & 0,967 & 0,937 \\
\hline $\mathrm{SO}_{4}{ }^{2-}$ & $-0,151$ & 0,762 & 0,604 & $-0,167$ & 0,771 & 0,622 \\
\hline $\mathbf{C E}$ & 0,847 & 0,501 & 0,969 & 0,863 & 0,477 & 0,973 \\
\hline $\begin{array}{l}\text { Variância } \\
\text { explicada } \\
\text { pelo fator } \\
(\%)\end{array}$ & 51,04 & 32,79 & & 48,08 & 37,06 & \\
\hline $\begin{array}{l}\text { Variância } \\
\text { acumulada } \\
(\%)\end{array}$ & \multicolumn{3}{|c|}{83.83} & \multicolumn{2}{|c|}{85.14} & \\
\hline
\end{tabular}

A técnica de análise de agrupamento multivariada, aplicada aos atributos explicados pelos fatores 1 e 2 da análise fatorial, agrupou as amostras com características semelhantes, ou seja, com águas quimicamente similares (Figuras $3 \mathrm{e}$ Fator $1\left(\mathrm{Mg}^{2+}, \mathrm{K}^{+}, \mathrm{Cl}^{-}, \mathrm{NO}_{2}^{-}, \mathrm{NO}_{3}^{-}{ }^{-} \mathrm{CE}\right)$

Período chuvoso (abril/ 2011)

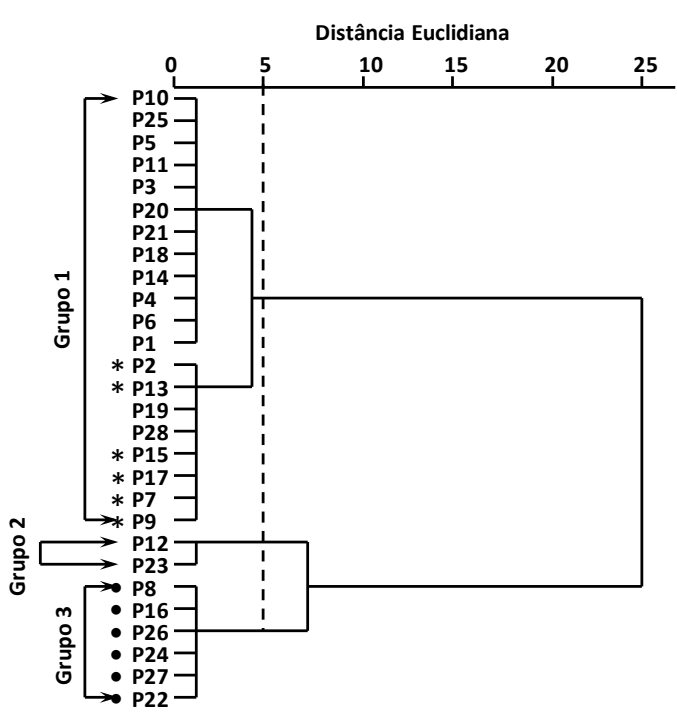

4). Os grupos obtidos e os atributos que os geraram foram submetidos à análise de variância One-Way ANOVA e apresentaram níveis de significância inferiores a 5\%, indicando a formação de um conjunto relativamente estável de grupos.

Período seco (outubro/ 2011)

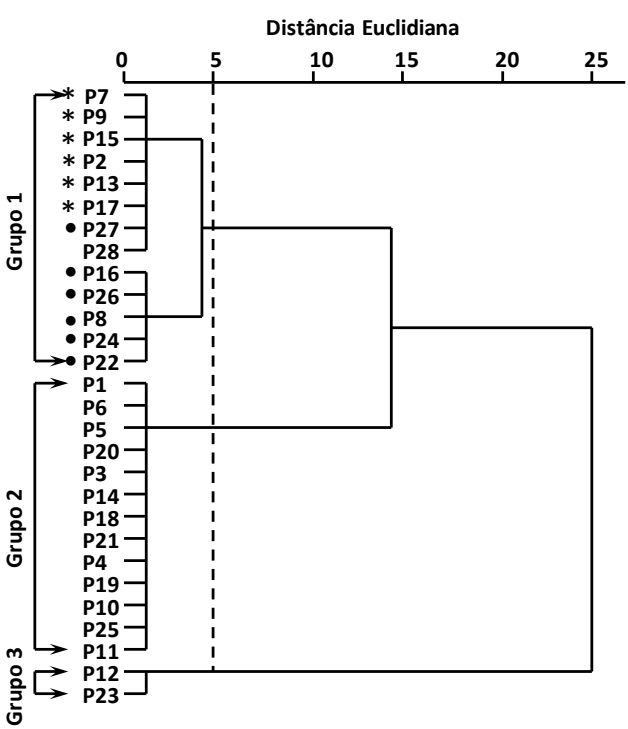

Figura 3 - Dendrograma resultante da Análise de Agrupamento das variáveis explicadas pelo fator 1 da Análise Fatorial nos períodos seco e chuvoso.

* amostras que migraram do grupo 1 no período seco, para o grupo 1 no período chuvoso e $\bullet$ do grupo 3 no período chuvoso, para o grupo 1 no período chuvoso. 

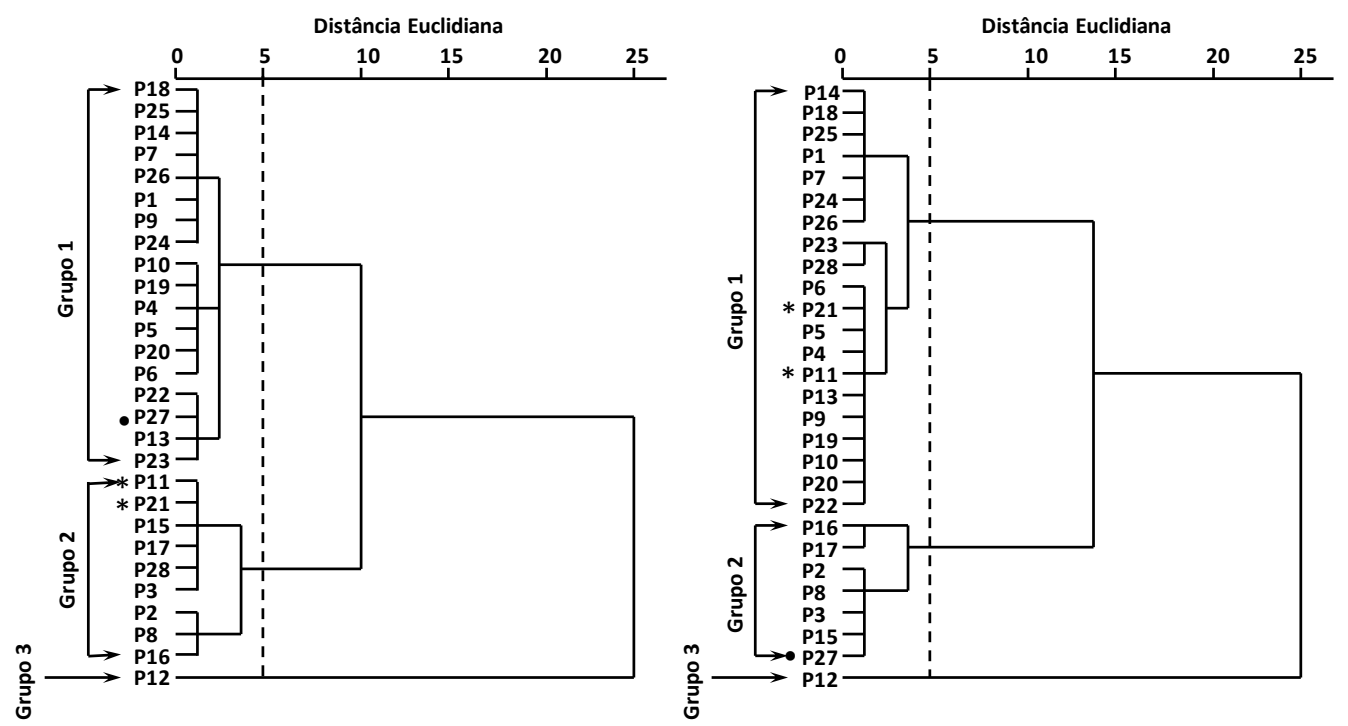

Figura 4 - Dendrograma resultante da Análise de Agrupamento das variáveis explicadas pelo fator 2 da Análise Fatorial nos períodos seco e chuvoso.

- amostras que migraram do grupo 1 no período seco, para o grupo 2 no período chuvoso e * do grupo 2 no período chuvoso, para o grupo 1 no período chuvoso.

O número de grupos foi definido pela primeira grande diferença entre os coeficientes reescalonados de agrupamento. Esses coeficientes explicitaram o ponto de corte cinco, onde observou-se a formação de três grupos homogêneos para cada período de amostragem e cada fator.

Os grupos definidos para o fator $1\left(\mathrm{Mg}^{2+}\right.$, $\mathrm{K}^{+}, \mathrm{Cl}^{-}, \mathrm{NO}_{2}{ }^{-}, \mathrm{NO}_{3}{ }^{-}$e $\mathrm{CE}$ ), nos períodos chuvoso (abril/ 2011) e seco (outubro/ 2011) (Figura 3), foram analisados em termos das concentrações de $\mathrm{NO}_{2}{ }^{-}$e $\mathrm{NO}_{3}{ }^{-}$. Estes elementos são indicadores de poluição de origem orgânica e apresentaram correlação linear forte com os demais atributos físico-químicos $\left(\mathrm{Mg}^{2+}, \mathrm{K}^{+} \mathrm{e}\right.$ $\mathrm{Cl}^{-}$e $\mathrm{CE}$ ).

De acordo com os atributos do fator 1 , o grupo 1 é composto por respectivamente 71 (20 poços) e $46 \%$ (13 poços) das amostras analisadas nos períodos chuvoso e seco.

No período chuvoso, $80 \%$ das amostras do grupo 1 (16 poços) atendem aos padrões de potabilidade definidos na Portaria $\mathrm{N}^{\circ}$ 2914/2011 do Ministério da Saúde. Nesse grupo, todas amostras apresentaram concentrações de $\mathrm{NO}_{2}{ }^{-}$variando de 0,51 a 1,15 $\mathrm{mg} / \mathrm{L}$ de $\mathrm{N}$, mas apenas o poço $\mathrm{P} 2$ apresentou concentração acima do valor máximo permissível $\left(1 \mathrm{mg} / \mathrm{L}\right.$ de $\left.\mathrm{N}^{-\mathrm{NO}_{2}}{ }^{-}\right)$. Quanto às concentrações de $\mathrm{NO}_{3}{ }^{-}$, apenas sete poços apresentaram valores entre 1,4 e $26,5 \mathrm{mg} / \mathrm{L}$ de N. Dentre estes, os poços P7, P10 e P15 apresentaram concentrações acima do valor máximo permissível $\left(10 \mathrm{mg} / \mathrm{L}\right.$ de $\left.\mathrm{N}-\mathrm{NO}_{3}{ }^{-}\right)$, que são de respectivamente 26,5, 23,6 e 11,1 mg/ L de N. Nesse grupo a CE das águas dos poços variou de 90 a $429 \mu \mathrm{S} / \mathrm{cm}$.

No período seco, não foram observadas concentrações de $\mathrm{NO}_{2}^{-}$, porém aumentaram as concentrações de $\mathrm{NO}_{3}{ }^{-}$nas águas dos poços. Os poços P2, P7, P9, P13, P15 e P17, antes pertencentes ao grupo 1 do período chuvoso, passaram a compor um novo grupo (grupo 1) no período seco, juntamente com os poços do grupo 3 do período chuvoso. Dos 13 poços agrupados, 10 não atenderam aos padrões de potabilidade quanto às concentrações de $\mathrm{N}$ $\mathrm{NO}_{3}{ }^{-}$(P7, P8, P9, P13, P15, P22, P24, P26, P27 e P28), com valores entre 10,7 e $105,2 \mathrm{mg} / \mathrm{L}$ de N. No grupo 1, do período seco, as CE's encontravam-se na faixa de 377 a $844 \mu \mathrm{S} / \mathrm{cm}$, com elevação em todos os poços, num intervalo de 40 (P16) a $114 \mu \mathrm{S} / \mathrm{cm}$ (P17).

No período chuvoso, quanto aos atributos do fator 1, apenas as amostras dos poços P12 e P23 compõem o grupo 2, caracterizado por 
águas mais mineralizadas, com $\mathrm{CE}$ de respectivamente 977 e $1.139 \mu \mathrm{S} / \mathrm{cm}$. Os poços P12 e P23 apresentaram concentrações de $\mathrm{NO}_{2}{ }^{-}$ de respectivamente 0,63 e $0,75 \mathrm{mg} / \mathrm{L}$ de $\mathrm{N}$, no entanto, apenas o poço $\mathrm{P} 23$ apresentou concentração de $\mathrm{NO}_{3}{ }^{-}$de $39,3 \mathrm{mg} / \mathrm{L}$ de $\mathrm{N}$, acima do valor máximo permissível.

No período seco, as duas amostras (P12 e P23) ainda permanecem agrupadas, porém, compondo o grupo 3. Nesse grupo também não foram observadas concentrações de $\mathrm{NO}_{2}{ }^{-}$e a concentração de $\mathrm{NO}_{3}{ }^{-}$do poço $\mathrm{P} 23$ elevou-se para $112 \mathrm{mg} / \mathrm{L}$ de N. As amostras dos poços P12 e P23 apresentaram CE de respectivamente 1.099 e $1.193 \mu \mathrm{S} / \mathrm{cm}$, indicando uma elevação de 122 e $54 \mu \mathrm{S} / \mathrm{cm}$ do período chuvoso para o seco.

O grupo 3 do período chuvoso agrupou seis poços (P8, P16, P22, P24, P26 e P29), caracterizado por águas de salinidade intermediária, com CE entre 522 e $751 \mu \mathrm{S} / \mathrm{cm}$. Dos seis poços analisados, apenas o poço P29 apresentou amostra que atende aos padrões de potabilidade, quanto aos íons $\mathrm{NO}_{2}{ }^{-}(0,87 \mathrm{mg} / \mathrm{L}$ de $\mathrm{N})$ e $\mathrm{NO}_{3}{ }^{-}(2,30 \mathrm{mg} / \mathrm{L}$ de $\mathrm{N})$. As demais amostras apresentaram concentrações de $\mathrm{NO}_{3}{ }^{-}$ na faixa de 13,00 a $40,30 \mathrm{mg} / \mathrm{L}$ de $\mathrm{N}$. As amostras dos poços P8, P16, P24 e P26 apresentaram concentrações de $\mathrm{NO}_{2}{ }^{-}$na faixa de 1,15 a 2,34 mg/ L de N.

No período seco, as amostras pertencentes ao grupo 3 no período chuvoso, passaram a compor o grupo 1 , juntamente com parte das amostras do grupo 1 do período chuvoso ( $\mathrm{P} 2$, P7, P9, P13, P15, P17 e P27). Não foram observadas concentrações de $\mathrm{NO}_{2}^{-}$, mas as de $\mathrm{NO}_{3}{ }^{-}$apresentaram-se acima do valor máximo permissível para cinco dos sete poços, numa faixa de 16,80 (poço P27) a 37,80 $\mathrm{mg} / \mathrm{L}$ de $\mathrm{N}$ (poço P7). Apenas os poços P2 e P17 apresentaram concentrações de respectivamente $2,80 \mathrm{e}<0,01 \mathrm{mg} / \mathrm{L}$ de N. As amostras dos sete poços apresentaram CE's de 377 (poço P15) a $482 \mu \mathrm{S} / \mathrm{cm}$ (poço P13), com elevações de 53 (poços P2 e P13) a $114 \mu \mathrm{S} / \mathrm{cm}$ (poço P17) do período chuvoso para o seco.

Os grupos definidos para o fator $2\left(\mathrm{Ca}^{2+}\right.$, $\mathrm{SO}_{4}{ }^{2-}$ e $\mathrm{HCO}_{3}{ }^{-}$), nos períodos chuvoso e seco (Figura 4), foram analisados em termos das concentrações de $\mathrm{HCO}_{3}^{-}$. A correlação linear forte entre este elemento e os demais $\left(\mathrm{Ca}^{2+} \mathrm{e}\right.$ $\left.\mathrm{SO}_{4}{ }^{2-}\right)$ sugere uma mistura entre águas de recarga recente na área de estudo e águas provenientes da dissolução dos minerais calcita $\left(\mathrm{CaCO}_{3}\right)$ e gipsita $\left(\mathrm{CaSO}_{4} .2 \mathrm{H}_{2} \mathrm{O}\right)$ presentes na Formação Santana da Chapada do Araripe.

O grupo 1, gerado a partir dos atributos do fator 2, é composto por respectivamente 64 (18 poços) e $71 \%$ (20 poços) das amostras analisadas nos períodos chuvoso e seco, o grupo 2, por 32 (9 poços) e $25 \%$ ( 7 poços) e o grupo 3, por apenas um poço em ambos os períodos.

O grupo 1, do período chuvoso, foi caracterizado pelas baixas concentrações de $\mathrm{HCO}_{3}{ }^{-}$, numa faixa $<0,01$ (poço P26) a 90,50 $\mathrm{mg} / \mathrm{L}$ (poço P6), quando comparadas com as do grupo 2, que foi de 109,80 (poço P21) a $271,4 \mathrm{mg} / \mathrm{L}$ (poço P16). O grupo 3, representado apenas pelo poço P12, apresentou a maior concentração, com 516,90 mg/ L.

Os grupos 1, 2 e 3, do período seco, apresentaram o mesmo arranjo dos do período chuvoso, com exceção apenas do poço P27, que era do grupo 1 no período chuvoso e passou a fazer parte do grupo 2 no período chuvoso e dos poços P11 e P21, que eram do grupo 2 no chuvoso e passaram para o grupo 1, no seco.

As figuras 5 e 6 mostram a geologia e a distribuição dos poços por grupo e por fator no período chuvoso e seco.

Os atributos do fator 1, indicadores de poluição das águas subterrâneas, sugerem que os poços identificados como do grupo 1 explotam, predominantemente, águas que atendem aos padrões de potabilidade quanto à concentração dos íons $\mathrm{Cl}^{-}, \mathrm{NO}_{2}{ }^{-}$e $\mathrm{NO}_{3}{ }^{-}$. Estes poços explotam o aquífero Rio da Batateira e proximidades de aluviões, nos municípios de Juazeiro do Norte, Crato e Barbalha. Os identificados como do grupo 2 são apenas dois, o P12, que também explota o aquífero Rio da Batateira, mas encontra-se nas proximidades do afloramento da Formação Santana e o P23, que explota o mesmo aquífero, mas nas proximidades de aluvião. Nestes poços as águas são as mais mineralizadas (maior CE) e apenas o poço P23 apresentou concentração de $\mathrm{NO}_{3}{ }^{-}$acima do valor máximo permissível. Já os do grupo 3, que explotam o aquífero Rio da Batateira e proximidades de aluviões, estão localizados principalmente na sede municipal de Juazeiro do Norte. 


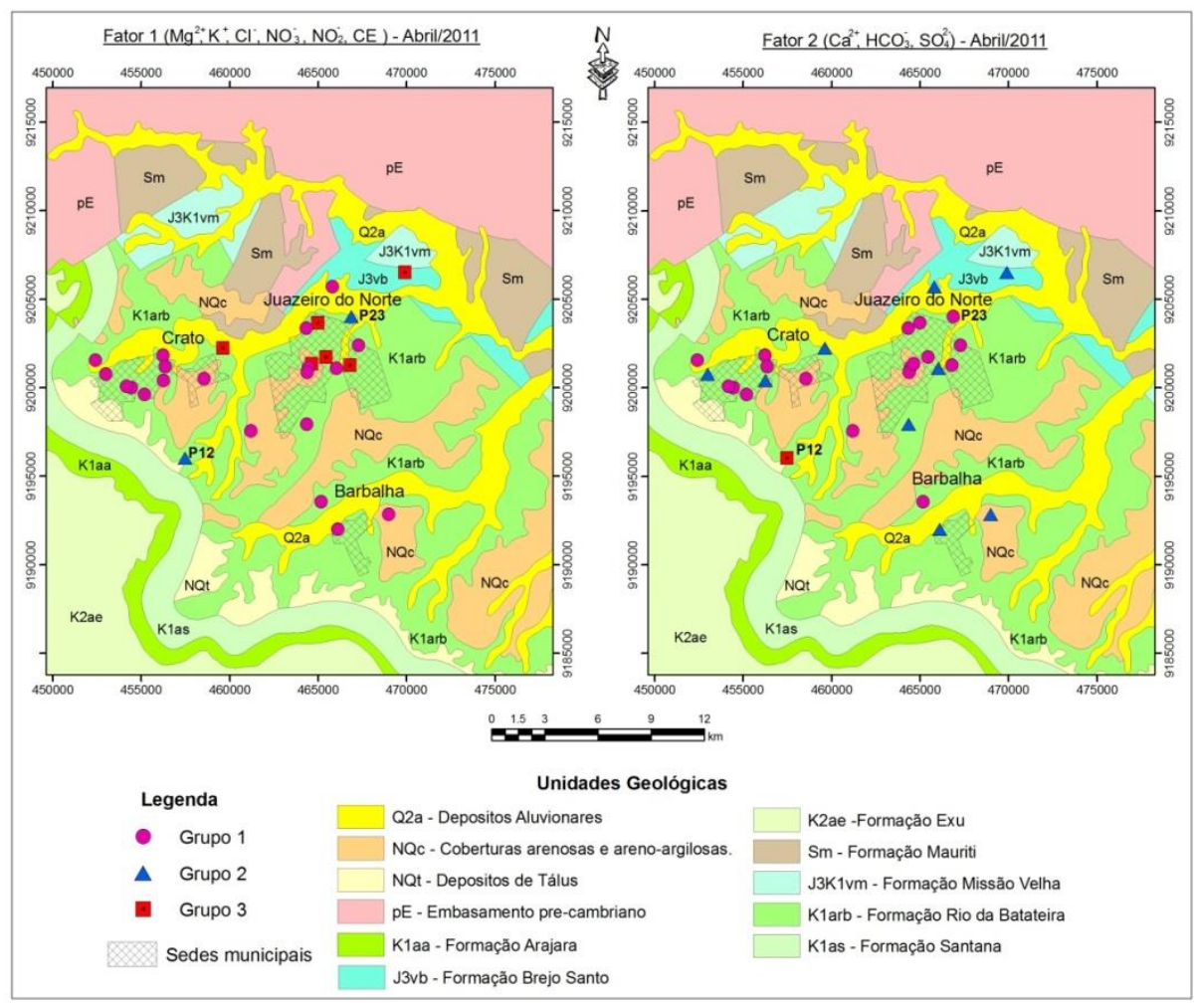

Figura 5 - Geologia e distribuição dos poços por grupo e por fator no período chuvoso.

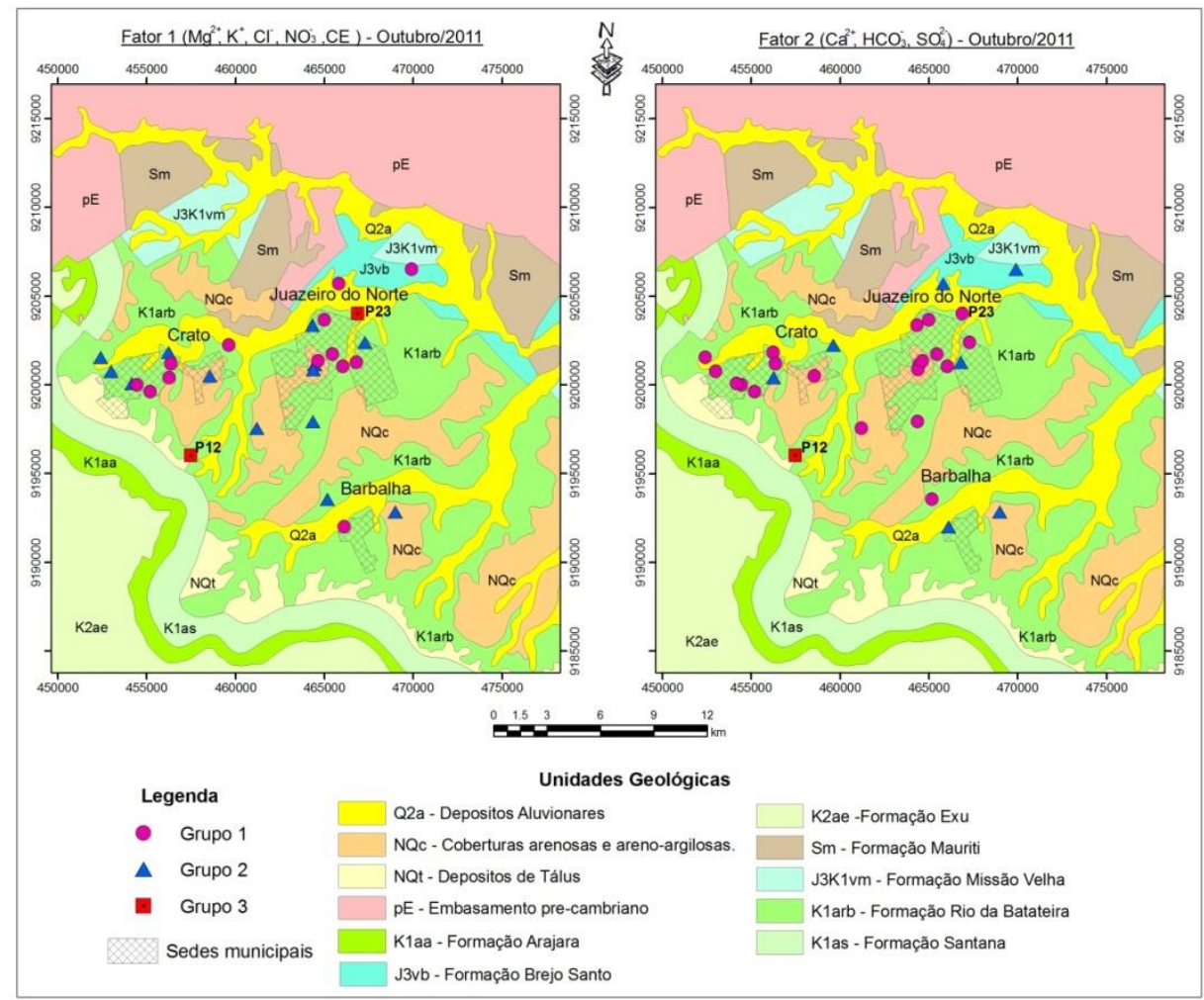

Figura 6 - Geologia e distribuição dos poços por grupo e por fator no período seco.

As águas explotadas por estes poços são de salinidade intermediária e apresentaram, predominantemente, as maiores concentrações de $\mathrm{NO}_{3}^{-}$e $\mathrm{NO}_{2}^{-}$, acima do valor máximo permissível.
Os atributos do fator 2 , indicadores da dissolução dos minerais calcita e gipsita, presentes na Formação Santana, sugerem que os poços do grupo 1, com localização semelhante a parte dos grupos 1 e 3 do Fator 1, 
explotam águas de recarga no vale, caracterizadas como de baixas concentrações de $\mathrm{HCO}_{3}{ }^{-}$. Os do grupo 2, que explotam o aquífero Rio da Batateira, nas proximidades das aluviões da principal rede de drenagem local, apresentam concentrações intermediárias de $\mathrm{HCO}_{3}^{-}$. Esta rede de drenagem recebe águas que lixiviam as encostas da chapada, onde aflora a Formação Santana, mas também drenam águas do vale, produzindo uma diluição, levando os íons a concentrações intermediárias. $\mathrm{O}$ grupo 3 foi representado apenas pelo poço P12, que explota o aquífero Rio da Batateira nas proximidades do afloramento da Formação Santana, com elevada concentração de $\mathrm{HCO}_{3}{ }^{-}$.

\section{CONCLUSÕES}

A análise fatorial e a análise de agrupamento multivariada contribuíram com o entendimento dos processos que interferem na qualidade das águas subterrâneas de CRAJUBAR nos períodos chuvoso e seco.

A análise fatorial aplicada a nove atributos físico-químicos das águas subterrâneas, nos períodos chuvoso e seco, mostrou que dois componentes respondem por aproximadamente $84 \%$ da variância total: o primeiro como indicador de poluição das águas subterrâneas por esgoto de origem orgânica, representado por seis atributos $\left(\mathrm{Mg}^{2+}, \mathrm{K}^{+}, \mathrm{Cl}^{-}, \mathrm{NO}_{2}^{-}, \mathrm{NO}_{3}{ }^{-} \mathrm{e}\right.$ $\mathrm{CE}$ ); e o segundo, como indicador da dissolução dos minerais calcita e gipsita $\left(\mathrm{Ca}^{2+}, \mathrm{SO}_{4}{ }^{2-} \mathrm{e}\right.$ $\mathrm{HCO}_{3}{ }^{-}$) presentes na Formação Santana da Chapada do Araripe.

A análise de agrupamento multivariada, aplicada tanto aos atributos do primeiro componente da análise fatorial, quanto ao do segundo, nos dois períodos, apresentou dendrogramas com formação de três grupos, compos- tos individualmente por amostras com diferentes faixas de concentrações.

Os dendrogramas gerados pelo agrupamento dos atributos do primeiro fator mostraram-se dinâmicos do período chuvoso para o seco, indicando: a evolução dos compostos nitrogenados nas águas, através de reações químicas de transformação do $\mathrm{NO}_{2}^{-}$para o $\mathrm{NO}_{3}$; o aumento da salinidade das águas devido o lançamento contínuo de esgoto bruto no período seco.

Os dendrogramas provenientes do agrupamento dos atributos do segundo fator mostraram-se estáveis, indicando que a mistura entre as águas de recarga recente na área de estudo e as provenientes da dissolução dos minerais calcita e gipsita, é um processo estacionário no horizonte de tempo observado.

Os resultados mostraram que o uso da análise fatorial, associada a análise de agrupamento multivariada, é importante no monitoramento e suporte a gestão da qualidade das águas subterrâneas.

\section{AGRADECIMENTOS}

Os autores agradecem a GOGERH (sede de Crato), pela disponibilização do seu banco de dados utilizado neste trabalho. Ao $\mathrm{CNPq}$ e à FUNCAP, pela bolsa de Desenvolvimento Científico e Tecnológico Regional (DCR) concedida à primeira autora (Número do Processo: DCR-0024-00908.01.00/13).

\section{REFERÊNCIAS}

ANDRADE, E.M.; PALÁCIO, H.A.; SOUZA I.H.; OLIVEIRA L.R.A.; GUERREIRO, M.J. Land use effects in groundwater composition of an alluvial aquifer (Trussu River, Brazil) by multivariate techniques. Environmental Research, v. 106, p. 170-177, 2008.

ANDRADE, E.M; LOPES, F.B.; PALÁCIO, H.A.Q.; NASCIMENTO, D. DO; ALEXANDRE, D.M.B. Land use and groundwater quality: The case of Baixo Acaraú Irrigated Perimeter, Brazil. Revista Ciência Agronômica, Fortaleza, v. 41, n. 2, p. 208-215, 2010.

ARAÚJO, A.O.; MENDONÇA, L.A.R.; LIMA, M.G. DE S.; FEITOSA, J.V.; SILVA, F.J., NESS, R.L.L; FRISCHKORN, H.; SIMPLÍCIO, A.A.F.; KERNTOPF, M.R. Modificações nas propriedades dos solos de uma área de manejo florestal na Chapada do Araripe. Revista Brasileira Ciência do Solo, v. 37, p. 754-762, 2013.

BRITO, L.T.L.; SILVA, A. DE S.; SRINIVASAN, V.S.;GALVÃO, C. DE O.; GHEYI, H.R. Uso de análise multivariada na classificação das fontes hídricas subterrâneas na bacia hidrográfica do Salitre. Revista Engenharia Agrícola, v. 26, n. 1, p. 36-44, 2006.

CALLEGARI-JACQUES, S.M. Bioestatística: Princípios e aplicações. Porto Alegre, Artemed,. 255 p., 2003.

CLOUTIER, V.; LEFEBVRE, R.; THERRIEN, R.; SAVARD, M.M . Multivariate statistical analysis of geochemical data as indicative of the hydrogeo chemical evolution of groundwater in a sedimentary rock aquifer system. Journal of Hydrology, [S.1.], v.353, p. 294-313, 2008.

COGERH - Companhia de Gestão dos Recursos Hídricos. Estudo de qualidade das águas subterrâneas da Bacia Araripe, Ceará. volume II - Anexos. 72 p., 2011.

COSTA, W.D. Resumo hidrogeológico da região centro-sul da Paraíba. Águas subterrâneas, v. 1, n. 2, p. 18-24, 1965.

EVERITT, B.S. \& DUNN, G. Applied multivariate analysis. London: Edward Arnold, 400 p., 1991.

FENZL, N. Processos Geoquímicos que determinam a 
composição química das águas naturais. In: FENZL, N. \& RAMOS, J.F. (Coordenadores). Introdução à Hidrogeoquímica. 1. ed. Belém: Universidade Federal do Pará, cap. 02. p. 33-46, 1988.

FERNANDES, F.B.P.; ANDRADE, E.M. DE.; FONTENELE , S. DE B.; MEIRELES, A.C.M.; RIBEIRO, J.A. Análise de agrupamento como suporte à gestão qualitativa da água subterrânea no semiárido cearense. Revista Agro@mbiente On-line, v. 4, n. 2, p. 86-95, 2010.

FERREIRA, D.F. Análise Multivariada. Lavras, Minas Gerais, 394 p., 1996.

FRANCA, R.M. DA; FRISCHKORN, H.; SANTOS, M.R.P.; MENDONÇA, L.A.R.; BESERRA, M. DA C. Contaminação de poços tubulares em Juazeiro do Norte-CE. Engenharia sanitária ambiental, v. 11, n. 1, p. 92-102, 2006.

FREEZE, R.A. \& CHERRY, J.A. Groundwater. New Jersey: Englewood Cliffs, Prentice Hall, 604 p., 1979.

GARRELS, R.M. \& MACKENZIE, F.T. Origin of the chemical composition of springs and lakes. In: Equilibrium concepts in natural water systems. American Chemical Society, Advances in Chemistry Series, n. 67, p. 222 - 242, 1967.

GONZALEZ-ERICO, E.; KAMPRATH, E.J.; NADERMAN, G.C.; SOARES, W.V. Effect of depth of lime incorporation on the growth of corn on an oxisol of central Brazil. Soil Science Society of America Journal, v.43, p.1155-1158, 1979.

HAIR JR., J.F.; ANDERSON, R.E.; TATHAN, R.L.; BLACK, W.C. Multivariate data analysis. New Jersey, Prentice Hall, 928 p., 1998.

HOFFMANN, R. Componentes principais e análise fatorial. Piracicaba, Escola Superior de Agricultura Luiz de Queiroz, 25 p. (Série Didática, 76)., 1992.

IBGE - Instituto Brasileiro de Geografia e Estatística. Censo geográfico 2010. Disponível em: www.ibge.gov.br/ cidadesat/topwindou.htm. Acessado em: 08set2015.

IPECE - Instituto de Pesquisa e Estratégia Econômica do Ceará. Perfil Básico Municipal. Disponível em: www.ipece.ce.gov.br/publicaçoes/perfil_basico/pbm_2013. Acessado em: 06set 2015.

LIMA, M.G. DE S.; MENDONÇA, L.A.R.; FRISCHKORN, H.; SASAKI, J.M.; GOMES, L. DE A.; SILVA, J. DAS G.P. DA. Estudo da composição química de precipitados em águas provenientes de poços profundos no município de Crato CE. Revista Brasileira de Recursos Hídricos, v. 16, p. 177-183, 2011.

LUCENA, L.R.F. DE; ROSA FILHO, E.F. DA; BITTENCOURT, A.V.L.; MONTAÑO, J.X. A migração de constituintes iônicos no aquífero Barreiras na região sul de Natal-RN, decorrente do quadro estrutural local - uma hipótese de trabalho. Revista Latino-Americana de Hidrogeologia, n. 4, p. 9-16, 2004.

MANLY, B.F.J. Multivariate statistical methods. 2.ed. London, Chapman \& Hall, 215 p., 1998.

MENDONÇA, L.A.R.; FRISCHKORN, H.; SANTIAGO, M.F.; MENDES FILHO, J. Estudo da conexão hidráulica dos aquíferos Rio da Batateira e Missão Velha por análise isotópica e de condutividade elétrica. Revista de Geologia (Fortaleza), v. 11, p. 15-22, 1998.

MENDONÇA, L.A.R.; SANTIAGO, M.O.; FRISCHKORN, H.; SASAKI, J.M. Problemas de cálcio na água de abastecimento de Nova Olinda CE. Engenharia Sanitária e Ambiental, v. 13, p. 298-305, 2008.

MACHADO, C.J.F. Modelagem geoquímica e de fluxos do sistema aquífero subterrâneo na Bacia Sedimentar do Araripe. Fortaleza, 2005. 159 p. Tese (Doutorado em Física), Universidade Federal do Ceará.

MACHADO, C.J.F.; SANTIAGO, M.M.F.; FRISCHKORN, H.; MENDES FILHO, J. Clustering of groundwaters by Qmode factor analysis according to their hydrogeochemical origin: A case study of the Cariri Valley (Northern Brazil) wells. Water SA (on-line), v. 34, n. 5, p. 651-656, 2008.

MOBUS, G. Qualigraf: software para interpretação de análises físico-químicas, versão Beta. Fundação Cearense de Meteorologia e Recursos Hídricos - FUNCEME. Fortaleza, 2003. Disponível em: http://www.funceme.br. Acessado em: 10dez2014.

PALÁCIO, H.A.Q.; ANDRADE, E.M. DE; LOPES, F.B.; ALEXANDRE, D M.B.; ARRAES, F.D.D. Salinidade da qualidade das águas superficiais da bacia do Curu, Ceará. Fortaleza-Ceará. Ciência Rural, v. 39, n. 9, p. 2494-2500, 2009.

PEARSON, R.W.; ABRUNA, F.; VICENT-CHANDLER, J.E. Effect of lime and nitrogen applications on downward movement of calcium and magnesium in two humid tropical soil of Puerto Rico. Soil Science, v. 93, p. 77-82, 1962.

PONTE, F.C. \& APPI, C.J. Proposta de revisão da coluna litoestratigráfica da bacia do Araripe. In: XXXVI CONGRESSO BRASILEIRO DE GEOLOGIA, 1990, Natal. Resumos... Natal: Sociedade Brasileira de Geologia, 1990, p. 211-226.

SALGADO, E.V.; ANDRADE, E.M. DE, FONTENELE, S. DE B., MEIRELES, A.C.M. Similaridade das variáveis hidroquímicas com o uso da análise multivariada, na Bacia do Salgado, Ceará. Revista Caatinga, v. 24, n. 3, p. 158-166, 2011.

SANTIAGO, M.M.F.; SANTIAGO, M.F.; SILVA, C.M.S.V.; MENDES FILHO, J.; FRISCHKORN, H. Characterization of groundwater in the Cariri (Ceará/Brazil) by environmental isotopes and electric conductivy. Radiocarbon, v. 39, n.1, p. 49-60, 1997.

SANTOS, A.C. Noções de Hidroquímica. In: FEITOSA, F.A.C.; MANOEL FILHO, J.; FEITOSA, E.C.; DEMETRIO, J.G.A. (Coordenação). Hidrogeologia: Conceitos e Aplicações. Rio de Janeiro: CPRM e LABHID, 3. ed. p. 325357, 2008.

SANTOS, M.R.P.; SANTIAGO, M.F.; MENDONÇA, L.A.R.; FRISCHKORN, H.; MENDES FILHO, J. Modelagem do transporte de cloreto proveniente de esgoto urbano em um aquífero sedimentar usando MT3D: o caso da bateria de poços de Juazeiro do Norte (CE). Engenharia Sanitária e Ambiental, v. 19, p. 283-292, 2014.

SILVA, C.J.C. DA. Influência antrópica na composição dos sedimentos da rede de drenagem natural em Juazeiro do Norte - CE. Fortaleza, 2013. 110 p. Dissertação (Mestrado em Desenvolvimento Regional Sustentável), Universidade Federal do Cariri.

TEIXEIRA, J.A. \& OLIVEIRA, S.P.B. Perfuração de poços tubulares e levantamento geológico. Petrolina, PE: SUDENE, Hidrogeologia, 22 p., 1962.

VEGA, M.; PARDO, R.; BARRADO, E.; DEBÁN, L. Assessement of seasonal and polluting effects on the quality of river water by exploratory data analysis. Water Research, v. 32, n. 12, p. 3581-3592, 1998.

VIDAL, A.C.; KIANG, C.H. Caracterização hidroquímica dos aquíferos da bacia de Taubaté. Revista Brasileira de Geociências, v. 32, n. 2, p. 267-276, 2002.

YIDANA, S.M.; OPHORI, D.; BANOENG-YAKUBO, B. A multivariate statistical analysis of surface water chemistry data. The Ankobra basin, Ghana. Journal of Environmental Management, n. 86, p. 80-87, 2008.

Manuscrito recebido em 30 de novembro de 2015 Revisado e aceito em 24 de novembro de 2016 